Bull. Mater. Sci., Vol. 39, No. 7, December 2016, pp. 1851-1860. (C) Indian Academy of Sciences.

\title{
X-ray structure, hydrogen bonding and lattice energy analysis of (2E)-1-(anthracen-9-yl)-3-(4-substitutedphenyl)prop-2-en-1-ones
}

\author{
VINUTHA V SALIAN ${ }^{1}$, B NARAYANA ${ }^{1}$, K BYRAPPA ${ }^{1}$, B K SAROJINI ${ }^{2}$ and RAJNI KANT ${ }^{3, *}$ \\ ${ }^{1}$ Department of Studies in Chemistry, Mangalore University, Mangalagangothri 574 199, India \\ ${ }^{2}$ Department of Studies in Chemistry - Industrial Chemistry Division, Mangalore University, \\ Mangalagangothri 574 199, India \\ ${ }^{3}$ X-ray Crystallography Laboratory, Post-Graduate Department of Physics and Electronics, \\ University of Jammu, Jammu Tawi 180 006, India
}

MS received 17 March 2015; accepted 26 April 2016

\begin{abstract}
E)-1-(anthracen-9-yl)-3-(4-chlorophenyl)prop-2-en-1-ones and (2E)-1-(anthracen-9-yl)-3-(4-nitrophenyl) prop-2-en-1-ones crystallize in the monoclinic crystal system with space group P2 1 c. Single-crystal X-ray diffraction data for both the compounds were collected on an $X^{\prime}$ Calibur CCD area detector diffractometer (Oxford Diffraction) using MoKa radiation ( $\lambda=0.7107 \AA$ ) at 293(2) K. The crystal structures were solved by direct methods and refined by full-matrix least-square procedures to a final $R$ value of 0.0468 [I] and 0.0486 [II]. The crystal structures as elucidated by $X$-ray diffraction methods show the presence of a few intermolecular interactions, and the nature and energetics associated with these interactions have been characterized using PIXEL software.
\end{abstract}

Keywords. Anthracene; prop-2-en-1-one; crystal structure; intermolecular interactions; lattice energy; PIXEL.

\section{Introduction}

Chalcone is an aromatic ketone and an enone that forms a central core for a variety of pharmacologically important heterocyclic compounds. Chalcones are an important class of secondary metabolites that are precursors of many naturally occurring plant pigments [1]. These small molecules are also used as starting materials in the synthesis of UV absorption filters in polymers, photorefractive polymers, photosensitizers in colour films, sweeteners in food technology and in holographic recording technology. Chalcones, considered as the precursors of flavonoids and isoflavones, are also known to be effective antimicrobial agents [2].

Natural and synthetic chalcones have been attracting great interest owing to their broad range of biological activities, such as antileishmanial [3] anti-invasive [4], antitubercular [5], antifungal [6], antimalarial [7], anticancer [8] and antiinflammatory activities [9]. They are biosynthetic precursors of triaryl pyridines [10], pyrazoles [11] and indazoles [12]. These $\alpha, \beta$-unsaturated ketones were found to be effective photosensitive materials and exhibit potential nonlinear optical properties [13].

Chalcones are also known to possess antioxidant character to various extents. Activated macrophages play a key role in inflammatory responses and release a variety of mediators,

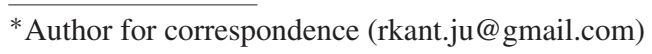

including nitric oxide (NO). NO is a potent vasodilator thatfacilitates leukocytic migration and formation of edema as well as leukocytic activity and cytokine production [2]. The crystal structures of some chalcone derivatives viz., 2,3-dibromo-1,3-bis(4-fluorophenyl)propan-1-one [14], 3-(3, 4-dimethoxyphenyl)-1-(4-fluorophenyl)prop-2-en-1-one, 2bromo-1-(4-methylphenyl)-3-[4-(methylsulphanyl) phenyl] prop-2-en-1-one [15], (2E)-1-(4-chlorophenyl)-3-[4-(propan2-yl)phenyl]prop-2-en-1-one [16] and 2-bromo-1-chlorophenyl-3-(4-methoxyphenyl)prop-2-en-1-one [17] have been reported. Keeping in view the wide range of activities of the chalcones, we report the crystal structure and lattice energy analysis of both the compounds.

\section{Experimental}

\subsection{Synthesis and crystallization}

To a mixture of 4-chlorobenzaldehyde $(1.4 \mathrm{~g}, 0.01 \mathrm{~mol})$ or 4-nitrobenzaldehyde $(1.5 \mathrm{~g}, 0.01 \mathrm{~mol})$ and 9-acetylanthracene $(2.2 \mathrm{~g}, 0.01 \mathrm{~mol})$ in ethanol $(50 \mathrm{ml}), 15 \mathrm{ml}$ of $10 \%$ sodium hydroxide solution was added and stirred at $0-5^{\circ} \mathrm{C}$ for $3 \mathrm{~h}$. The process of synthesis is depicted in the reaction scheme. The precipitate formed was collected by filtration and purified by recrystallization from ethanol. Single crystals of I and II were grown from ethanol by slow evaporation method (compound I: M.P. 429-431 K; compound II: M.P. 432-434 K). 

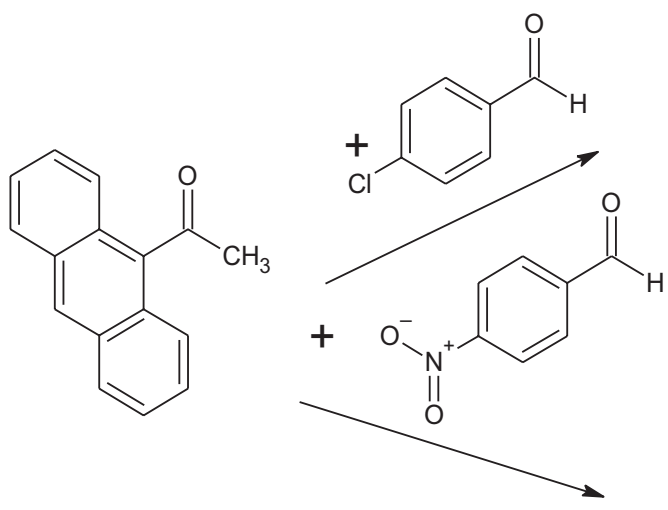<smiles>O=C(/C=C/c1ccc(Cl)cc1)c1c2ccccc2cc2ccccc12</smiles>

I<smiles>O=C(/C=C/c1ccc([N+](=O)[O-])cc1)c1c2ccccc2cc2ccccc12</smiles>

II

Reaction scheme for the title compounds.

\subsection{Data collection and refinement details}

Single-crystal X-ray diffraction data of both the compounds were collected on an $X^{\prime}$ Calibur CCD area detector diffractometer (Oxford Diffraction) using MoKa radiation $(\lambda=$ $0.7107 \AA$ ) at 293(2) K [18]. The crystal structures were solved by direct methods using SHELXS97 [19] and fullmatrix least-square structure refinement against $F^{2}$ was performed using SHELXL97 [19] software present in the program suite WinGX [20]. All the non-hydrogen atoms were refined anisotropically and all the hydrogen atoms were geometrically fixed and allowed to ride on their parent $\mathrm{C}$ atoms with $\mathrm{C}-\mathrm{H}=0.93 \AA$ for both the compounds $\left[U_{\text {iso }}(\mathrm{H})\right.$ $\left.=1.2 U_{\mathrm{eq}}(\mathrm{C})\right]$. Detailed crystallographic data for compounds I and II have been deposited at the Cambridge Crystallographic Data Centre (CCDC No. 1045455 for I and CCDC No. 1045454 for II) and are available on request. Crystal data collection parameters and structure refinement details for compounds I and II are summarized in table 1. Details of intermolecular hydrogen bonding for I and II are given in table 2 and $\pi-\pi$ interaction geometry in table 3 .

\subsection{Computations}

Geometrical calculations were performed using PLATON [21] and PARST [22] software. PIXEL calculations were performed in order to estimate the nature and energies associated with the intermolecular interactions, which will enable us to explore the role of these interactions in the stabilization of the crystal lattice. PIXELC calculations as incorporated in the Couloumb-London-Pauli (CLP) program [23] were performed to determine intermolecular interaction energies and lattice energy. PIXEL calculations allow the analysis of lattice and intermolecular interaction energies between pairs of molecules in terms of coulombic, polarization, dispersion and repulsion contributions. The total PIXEL energy, which is the sum of these four energy contributions, gives an indication of the overall interaction energy for a particular dimer and for crystal packing. However, it is the separation of these energies into the four different terms that makes this method a powerful tool for crystal structure analysis.

\section{Theoretical calculations}

To get a better understanding of the contribution of intermolecular interactions to the crystal packing, it is important to get a quantitative evaluation of these interactions. Calculation of the lattice energy not only offers a possible way for polymorph prediction but may also help understand the supramolecular chemistry and self-assembly during the nucleation and crystal growth processes and helps predict the melting and solubility behaviour of the compounds. The lattice energy of the title compound was calculated by PIXELC module in CLP computer program package (version 13.2.2012) [23]. The total lattice energy is partitioned into its coulombic, polarization, dispersion and repulsion contributions. In CLP program, the coulombic terms are handled by Coulomb's law while the polarization terms are calculated in the linear dipole approximation, with the incoming electric field acting on local polarizabilities and generating a dipole with its associated dipole 
Table 1. Experimental data for compounds I and II.

\begin{tabular}{|c|c|c|}
\hline & I & II \\
\hline \multicolumn{3}{|l|}{ Crystal data } \\
\hline CCDC no. & 1045455 & 1045454 \\
\hline Crystal description & White & White \\
\hline Crystal size & $0.3 \times 0.2 \times 0.2 \mathrm{~mm}^{3}$ & $0.3 \times 0.2 \times 0.2 \mathrm{~mm}^{3}$ \\
\hline Empirical formula & $\mathrm{C}_{23} \mathrm{H}_{15} \mathrm{Cl}_{1} \mathrm{O}_{1}$ & $\mathrm{C}_{23} \mathrm{H}_{15} \mathrm{~N}_{1} \mathrm{O}_{3}$ \\
\hline Formula weight & 342.80 & 353.36 \\
\hline Radiation, wavelength & $\operatorname{Mo} K \alpha, 0.71073 \AA$ & $\operatorname{Mo} K \alpha, 0.71073 \AA$ \\
\hline \multirow[t]{4}{*}{ Unit cell dimensions } & $a=14.595(2) \AA$ & $a=13.2972(13) \AA$ \\
\hline & $b=11.0790(8) \AA$ & $b=12.6236(16) \AA$ \\
\hline & $c=11.435(2) \AA$ & $c=11.0415(11) \AA$ \\
\hline & $\beta=112.98(2)^{\circ}$ & $\beta=105.667(9)^{\mathrm{o}}$ \\
\hline Crystal system & Monoclinic & Monoclinic \\
\hline Space group & $\mathrm{P} 2{ }_{1} / \mathrm{c}$ & $\mathrm{P} 2{ }_{1} / \mathrm{c}$ \\
\hline Unit cell volume & $1702.3(4) \AA^{3}$ & $1784.6(3) \AA^{3}$ \\
\hline No. of molecules per unit cell, $Z$ & 4 & 4 \\
\hline Temperature & 293(2) K & 293(2) K \\
\hline Absorption coefficient & $0.231 \mathrm{~mm}^{-1}$ & $0.088 \mathrm{~mm}^{-1}$ \\
\hline$F(000)$ & 712 & 736 \\
\hline \multicolumn{3}{|l|}{ Data collection } \\
\hline Diffractometer & $\begin{array}{l}\text { X'calibur system } \\
\text { (Oxford Diffraction make, U.K.) }\end{array}$ & $\begin{array}{l}\text { X'calibur system } \\
\text { (Oxford Diffraction make, U.K.) }\end{array}$ \\
\hline Absorption correction & $\begin{array}{l}\text { Multi-scan } \\
\text { (CrysAlis RED; } \\
\text { Oxford Diffraction, 2010) }\end{array}$ & $\begin{array}{l}\text { Multi-scan } \\
\text { (CrysAlis RED; } \\
\text { Oxford Diffraction, 2010) }\end{array}$ \\
\hline$T_{\min }, T_{\max }$ & $0.89969,1.00000$ & $0.84990,1.00000$ \\
\hline Reflections collected/unique & $4653 / 2506$ & $7062 / 3497$ \\
\hline Reflections observed $(I>2 \sigma(I))$ & 1678 & 1448 \\
\hline Scan mode & $\omega$ scan & $\omega$ scan \\
\hline$\theta$ Range for entire data collection & $3.55^{\circ}<\theta<26.00^{\circ}$ & $3.57^{\circ}<\theta<26.00^{\circ}$ \\
\hline \multirow[t]{3}{*}{ Range of indices } & $h=-17$ to 7 & $h=-15$ to 16 \\
\hline & $k=-13$ to 10 & $k=-15$ to 9 \\
\hline & $l=-10$ to 14 & $l=-12$ to 13 \\
\hline Reflections collected/unique & $4653 / 2506$ & $7062 / 3497$ \\
\hline Reflections observed $(I>2 \sigma(I))$ & 1678 & 1448 \\
\hline$R_{\text {int }}$ & 0.0232 & 0.0468 \\
\hline$R_{\text {sigma }}$ & 0.0411 & 0.1061 \\
\hline \multicolumn{3}{|l|}{ Refinement } \\
\hline Refinement & Full-matrix least squares on $F^{2}$ & Full-matrix least squares on $F^{2}$ \\
\hline No. of parameters refined & 226 & 244 \\
\hline No. of restraints & 0 & 0 \\
\hline$R\left[F^{2}>2 \sigma\left(F^{2}\right)\right]$ & 0.0468 & 0.0486 \\
\hline$w R\left(F^{2}\right)$ & 0.0913 & 0.0751 \\
\hline Goodness-of-fit $S$ & 1.045 & 0.878 \\
\hline$(\Delta / \sigma)_{\max }$ & 0.001 (for z C5) & 0.004 (for $\mathrm{U}^{33} \mathrm{C} 17$ ) \\
\hline Final residual electron density & $-0.234<\Delta \rho<0.123$ e $\AA^{-3}$ & $-0.147<\Delta \rho<0.136 \mathrm{e} \AA^{-3}$ \\
\hline Software for refinement & SHELXL97 [Sheldrick, 2008] & SHELXL97 [Sheldrick, 2008] \\
\hline
\end{tabular}

separation energy; dispersion terms are simulated in London's inverse sixth power approximation, involving ionization potentials and polarizabilities; repulsion is presented as a modulated function of wavefunction overlap. All the stabilizing molecular pairs involved in crystal packing were selected from the mlc output file, which is generated after PIXEL 
Table 2. Geometry of $\mathrm{C}-\mathrm{H} . . . \mathrm{O}$ and $\mathrm{C}-\mathrm{H} . \ldots \pi$ hydrogen bonds.

\begin{tabular}{|c|c|c|c|c|}
\hline D-H...A & D-H $(\AA)$ & D...A $(\AA)$ & H. ..A $(\AA)$ & D-H...A $\left({ }^{\circ}\right)$ \\
\hline \multicolumn{5}{|l|}{ I } \\
\hline $\mathrm{C} 5-\mathrm{H} 5 \ldots . \mathrm{O} 1^{\mathrm{i}}$ & 0.93 & 2.55 & $3.392(3)$ & 150 \\
\hline $\mathrm{C} 7-\mathrm{H} 7 \ldots{ }^{\mathrm{i}}$ & 0.97 & 2.43 & $3.305(4)$ & 156 \\
\hline $\mathrm{C} 8-\mathrm{H} 8 . . \mathrm{Cg} 1^{\mathrm{ii}}$ & 0.93 & 3.28 & $3.964(4)$ & 132 \\
\hline $\mathrm{C} 15-\mathrm{H} 15 \ldots \mathrm{Cg} 2^{\mathrm{iii}}$ & 0.93 & 3.09 & $3.983(4)$ & 161 \\
\hline \multicolumn{5}{|c|}{ Symmetry code: (i) $\mathrm{x},-\mathrm{y}-1 / 2, \mathrm{z}-1 / 2$, (ii) $\mathrm{x},-\mathrm{y}+1 / 2, \mathrm{z}-1 / 2$ and (iii) $-\mathrm{x}+1, \mathrm{y}+1 / 2,-\mathrm{z}+3 / 2$} \\
\hline \multicolumn{5}{|l|}{ II } \\
\hline $\mathrm{C} 2-\mathrm{H} 2 \ldots 3^{\mathrm{i}}$ & 0.93 & 2.50 & $3.361(3)$ & 153 \\
\hline $\mathrm{C} 5-\mathrm{H} 5 \ldots \mathrm{O} 1^{\mathrm{ii}}$ & 0.93 & 2.57 & $3.400(3)$ & 149 \\
\hline $\mathrm{C} 7-\mathrm{H} 7 \ldots \mathrm{O} 1^{\mathrm{ii}}$ & 0.93 & 2.40 & $3.273(3)$ & 157 \\
\hline $\mathrm{C} 13-\mathrm{H} 13 \ldots \mathrm{Cg} 1^{\mathrm{iii}}$ & 0.93 & 2.95 & $3.754(3)$ & 145 \\
\hline $\mathrm{C} 8-\mathrm{H} 8 \ldots \mathrm{Cg} 2^{\mathrm{iv}}$ & 0.93 & 3.12 & $3.949(3)$ & 150 \\
\hline
\end{tabular}

In I, $\mathrm{Cg} 1$ and $\mathrm{Cg} 2$ represent the centre of gravity of phenyl rings $\mathrm{C} 11-\mathrm{C} 16$ and $\mathrm{C} 18-\mathrm{C} 23$, respectively. In II, $\mathrm{Cg} 1$ and $\mathrm{Cg} 2$ represent the centre of gravity of nitrophenyl ring and phenyl ring $\mathrm{C} 18-\mathrm{C} 23$, respectively.

Table 3. Geometry of $\pi-\pi$ interactions. $\mathrm{Cg} I \ldots \mathrm{Cg} J$ represent the distance between the ring centroids; $\mathrm{Cg} I \ldots P$, the perpendicular distance of the centroid of one ring from the plane of the other; $\alpha$ is the dihedral angle between the planes of rings $I$ and $J ; \beta$ is the angle between normal to the centroid of ring $I$ and the line joining ring centroids; $\Delta$ is the displacement of the centroid of ring $J$ relative to the intersection point of the normal to the centroid of ring $I$ and the least-square plane of ring $J$.

\begin{tabular}{|c|c|c|c|c|c|}
\hline & $\mathrm{Cg} I \ldots \mathrm{Cg} J(\AA)$ & $\mathrm{Cg} I \ldots P(\AA)$ & $\alpha\left(^{\circ}\right)$ & $\beta\left(^{\circ}\right)$ & $\Delta(\AA)$ \\
\hline \multicolumn{6}{|l|}{ I } \\
\hline $\mathrm{Cg} 3 \ldots \mathrm{Cg} 3^{\text {iv }}$ & $3.955(2)$ & 3.480 & 0.00 & 28.39 & 1.87 \\
\hline $\mathrm{Cg} 4 \ldots \mathrm{Cg} 4^{\mathrm{v}}$ & $3.891(2)$ & 3.479 & 0.02 & 26.60 & 1.74 \\
\hline $\mathrm{Cg} 1 \ldots \mathrm{Cg} 2^{\mathrm{V}}$ & $3.857(2)$ & 3.402 & 2.79 & 25.33 & 1.81 \\
\hline \multicolumn{6}{|c|}{ Symmetry code: (iv) $-x,-y,-z+1$ and (v) $-x+1,-y+1,-z+1$} \\
\hline \multicolumn{6}{|l|}{ II } \\
\hline $\mathrm{Cg} 1 \ldots \mathrm{Cg} 1^{\text {iv }}$ & $3.824(2)$ & 3.444 & 0.00 & 25.76 & 1.66 \\
\hline $\mathrm{Cg} 4 \ldots \mathrm{Cg} 4^{\mathrm{v}}$ & $3.761(2)$ & 3.512 & 0.00 & 20.98 & 1.34 \\
\hline $\mathrm{Cg} 3 \ldots \mathrm{Cg} 2^{\mathrm{v}}$ & $3.782(2)$ & 3.517 & 1.50 & 20.34 & 1.39 \\
\hline \multicolumn{6}{|c|}{ Symmetry code: (iv) $-x,-y,-z+1$ and (v) $-x+1,-y+1,-z+1$} \\
\hline
\end{tabular}

In $\mathbf{I}, \mathrm{Cg} 1$ and $\mathrm{Cg} 2$ represent the centre of gravity of phenyl rings $\mathrm{C} 11-\mathrm{C} 16$ and $\mathrm{C} 18$ $\mathrm{C} 23$, respectively, whereas $\mathrm{Cg} 3$ represents the centre of gravity of chlorophenyl ring and $\mathrm{Cg} 4$ represents the centre of gravity of phenyl ring $(\mathrm{C} 10 / \mathrm{C} 11 / \mathrm{C} 16 / \mathrm{C} 17 / \mathrm{C} 18 / \mathrm{C} 23)$.

In II, $\mathrm{Cg} 1$ represents the centre of gravity of nitrophenyl ring; $\mathrm{Cg} 2$ represents the centre of gravity of ring $\mathrm{C} 18-\mathrm{C} 23$; $\mathrm{Cg} 3$ represents the centre of gravity of $\mathrm{C} 11-\mathrm{C} 16$ ring and $\mathrm{Cg} 4$ represents the centre of gravity of $\mathrm{C} 10 / \mathrm{C} 11 / \mathrm{C} 16 / \mathrm{C} 17 / \mathrm{C} 18 / \mathrm{C} 23 \mathrm{ring}$.

energy calculations, and were analysed with their interaction energies. The symmetry operator and centroid-centroid distance along with coulombic, polarization, dispersion, repulsion and total interaction energies between the molecular pairs are presented in table 4 . The values of lattice energy for both the compounds are presented in table 5 . The molecular pairs are arranged in decreasing order of their stabilization energies. The PIXEL method has been preferred for the 
Table 4. Significant interaction energies $\left(\mathrm{kcal} \mathrm{mol}^{-1}\right)$ between molecular pairs related by a symmetry operation and the associated intermolecular interactions in both the compounds.

\begin{tabular}{|c|c|c|c|c|c|c|c|c|}
\hline Motif & $\begin{array}{c}\text { Centroid } \\
\text { distance }(\AA)\end{array}$ & $E_{\text {coul }}$ & $E_{\mathrm{pol}}$ & $E_{\mathrm{disp}}$ & $E_{\text {rep }}$ & $E_{\text {tot }}$ & Symmetry & $\begin{array}{l}\text { Important } \\
\text { interactions }\end{array}$ \\
\hline \multicolumn{9}{|c|}{ Compound I } \\
\hline 1 & 9.477 & -3.22 & -1.60 & -14.84 & 8.58 & -11.06 & $-1-x,-1-y, 1-z$ & $\pi-\pi$ \\
\hline 2 & 5.924 & -3.82 & -2.46 & -11.64 & 7.43 & -10.47 & $x,-1 / 2-y,-1 / 2+z$ & $\begin{array}{l}\mathrm{C} 5-\mathrm{H} 5 \ldots \mathrm{O} 1 \\
\mathrm{C} 7-\mathrm{H} 7 \ldots \mathrm{O} 1\end{array}$ \\
\hline 3 & 9.240 & -2.22 & -0.86 & -11.26 & 6.14 & -8.19 & $-x,-y, 1-z$ & $\begin{array}{l}\mathrm{C} 12 \ldots \mathrm{Cl} 1 \\
\mathrm{C} 13 \ldots \mathrm{Cl} 1\end{array}$ \\
\hline 4 & 7.445 & -1.36 & -0.84 & -8.00 & 4.06 & -6.14 & $-1-x,-y, 1-z$ & $\begin{array}{l}\mathrm{C} 20-\mathrm{H} 20 \ldots \mathrm{C} 1 \\
\mathrm{C} 21-\mathrm{H} 21 \ldots \mathrm{C} 6 \\
\mathrm{C} 21-\mathrm{H} 21 \ldots \mathrm{C} 7\end{array}$ \\
\hline 5 & 8.919 & -1.38 & -0.84 & -6.09 & 3.77 & -4.54 & $-1-x,-1 / 2+y, 1 / 2-z$ & $\begin{array}{l}\mathrm{C} 19-\mathrm{H} 19 \ldots \mathrm{Cg} 3 \\
\mathrm{C} 15-\mathrm{H} 15 \ldots \mathrm{Cg} 2\end{array}$ \\
\hline 6 & 9.542 & -0.23 & -0.47 & -4.61 & 1.84 & -3.51 & $-x,-1 / 2+y, 3 / 2-z$ & $\begin{array}{c}\mathrm{C} 12-\mathrm{H} 12 \ldots \mathrm{C} 2 \\
\mathrm{C} 8-\mathrm{H} 8 \ldots \mathrm{Cl} 1\end{array}$ \\
\hline 7 & 11.079 & -0.93 & -0.50 & -4.06 & 2.44 & -3.08 & $x,-1+y, z$ & $\begin{array}{l}\mathrm{C} 13-\mathrm{H} 13 \ldots \mathrm{Cl} 1 \\
\mathrm{C} 14-\mathrm{H} 14 \ldots \mathrm{Cl} 1\end{array}$ \\
\hline 8 & 11.111 & -0.86 & -0.26 & -2.34 & 0.91 & -2.58 & $x, 1 / 2-y, 1 / 2+z$ & $\mathrm{C} 2-\mathrm{H} 2 \ldots \mathrm{Cl} 1$ \\
\hline \multicolumn{9}{|c|}{ Compound II } \\
\hline 1 & 5.743 & -4.85 & -2.60 & -12.71 & 8.03 & -12.14 & $x, 1 / 2-y, 1 / 2+z$ & 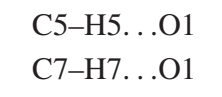 \\
\hline 2 & 9.723 & -2.74 & -1.36 & -14.43 & 7.00 & -11.54 & $2-x,-y, 1-z$ & $\pi-\pi$ \\
\hline 3 & 8.983 & -1.15 & -0.98 & -9.63 & 4.51 & -7.24 & $1-x, 1-y, 1-z$ & 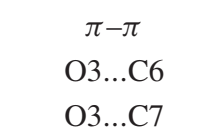 \\
\hline 4 & 7.391 & -0.79 & -0.67 & -7.38 & 3.66 & -5.18 & $2-x, 1-y, 1-z$ & $\begin{array}{c}\mathrm{C} 14-\mathrm{H} 14 \ldots \mathrm{C} 2 \\
\mathrm{C} 13-\mathrm{H} 13 \ldots \mathrm{Cg} 1\end{array}$ \\
\hline 5 & 9.450 & -1.05 & -0.76 & -5.69 & 3.13 & -4.37 & $2-x, 1 / 2+y, 3 / 2-z$ & $\begin{array}{l}\mathrm{C} 15-\mathrm{H} 15 \ldots \mathrm{Cg} 1 \\
\mathrm{C} 19-\mathrm{H} 19 \ldots \mathrm{Cg} 3\end{array}$ \\
\hline 6 & 10.112 & -1.09 & -0.57 & -3.85 & 1.58 & -3.94 & $1-x,-1 / 2+y, 1 / 2-z$ & C8-H8...O2 \\
\hline
\end{tabular}

Table 5. PIXELC lattice energy calculation output $\left(\mathrm{kcal} \mathrm{mol}^{-1}\right)$.

\begin{tabular}{lccccc}
\hline & $E_{\text {coul }}$ & $E_{\text {pol }}$ & $E_{\text {disp }}$ & $E_{\text {rep }}$ & $E_{\text {tot }}$ \\
\hline Compound I & -11.02 & -6.12 & -47.75 & 25.81 & -39.08 \\
Compound II & -11.61 & -5.62 & -43.76 & 22.87 & -38.12 \\
\hline
\end{tabular}

quantification of intermolecular interactions, primarily because of the following reasons:

(1) it is computationally less demanding [23];

(2) it allows partitioning of total interaction energy into corresponding coulombic, polarization, dispersion and repulsion contribution, which facilitates a better understanding of the nature of intermolecular interactions contributing towards the crystal packing [24];
(3) the energies obtained from PIXEL calculation are generally comparable with high-level quantum mechanical calculations [25,26].

\section{Results and discussion}

ORTEP diagrams of the compounds were generated using ORTEP32 [27] and packing diagram was generated using PLATON [21] software. Both the compounds crystallize in the monoclinic crystal system with space group $\mathrm{P} 2_{1} / \mathrm{c}$. The bond distances of compounds I and II show normal values [28] and are comparable with those observed in related structures [14-17].

The molecular structure of $\mathbf{I}$ is shown in figure 1. In title compound I, $\mathrm{C}_{23} \mathrm{H}_{15} \mathrm{Cl}_{1} \mathrm{O}_{1}$, the prop-2-en-1-one unit is planar 


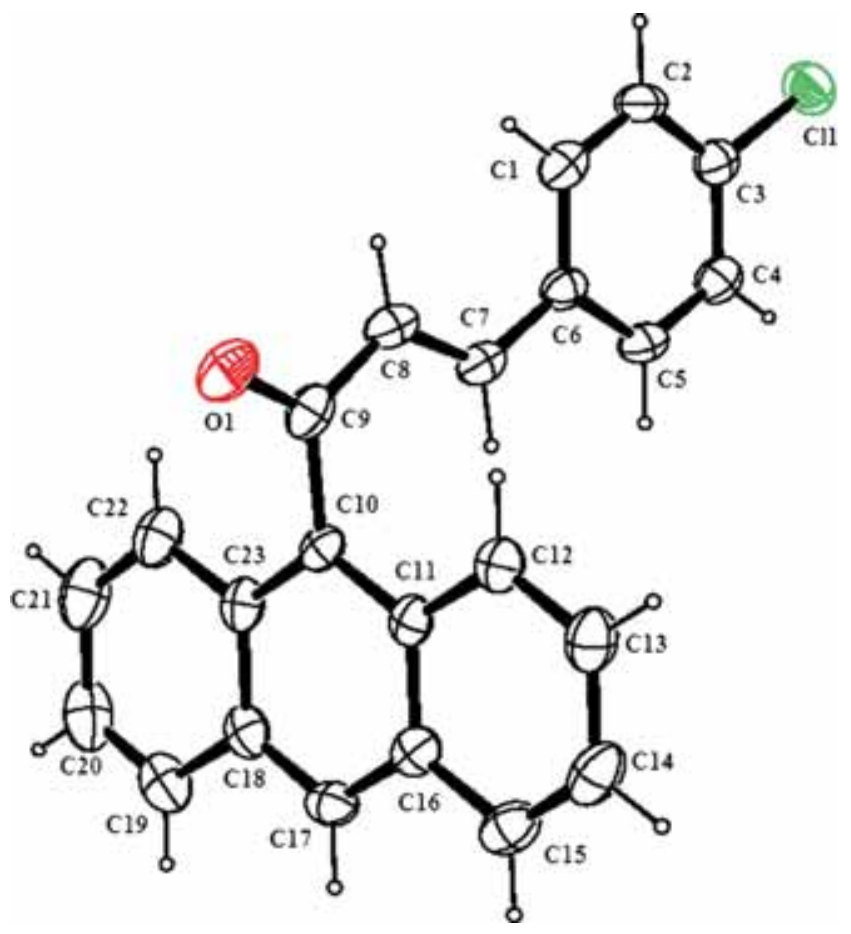

Figure 1. Molecular structure of $\mathbf{I}$, showing the atomic labelling scheme. Displacement ellipsoids are drawn at $30 \%$ probability level.

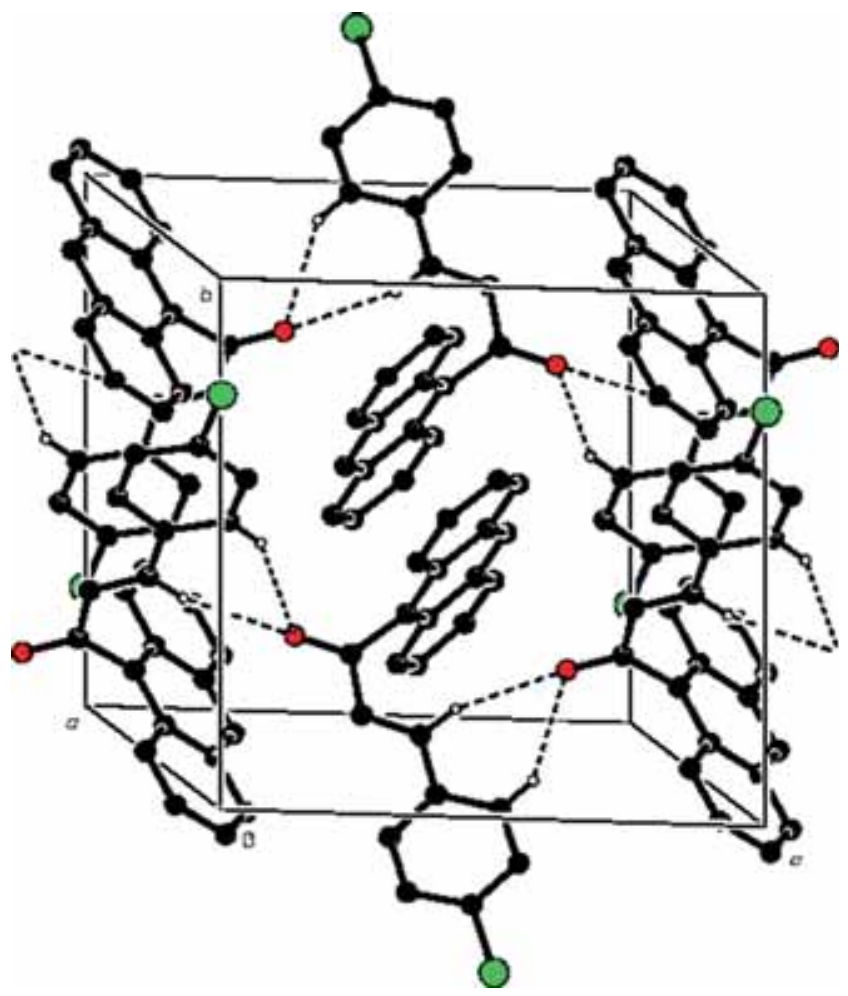

Figure 2. Crystal packing of compound I, viewed along the $a$ axis, showing hydrogen bonding (dashed lines). and it makes dihedral angles of $1.52(15)^{\circ}$ and $80.52(17)^{\circ}$, respectively, with the 4-chlorophenyl ring and the anthracene ring system. In compound $\mathbf{I}$, the anthracene ring system is planar and the molecule is twisted as indicated by the interplanar angle between the 4-chlorophenyl ring and the anthracene ring system, which is $79.32(6)^{\circ}$. The pro-2-en-1-one unit (C7-C9/O1) is planar as evidenced by the torsion angle O1-C9-C $8-\mathrm{C} 7$ of $174.8(3)^{\circ}$. The length of the double bond $\mathrm{C} 9=\mathrm{O} 1$ is confirmed by the respective distance of $1.228(3) \AA$. Molecule I adopts a trans-(-)gauche-trans (tgt) conformation [torsion angles $\left({ }^{\circ}\right)$ : $\mathrm{C} 6-\mathrm{C} 7-\mathrm{C} 8-\mathrm{C} 9,-178.4(2)^{\circ}$; $\mathrm{C} 7-\mathrm{C} 8-\mathrm{C} 9-$ $\left.\mathrm{C} 10,-4.8(4)^{\circ} ; \mathrm{C} 7-\mathrm{C} 8-\mathrm{C} 9-\mathrm{O} 1,174.8(3)^{\circ}\right]$. In this crystal, adjacent molecules are interconnected through $\mathrm{C}-\mathrm{H}$...O hydrogen bonds shown in figure 2 . The crystal structure is further stabilized by $\mathrm{C}-\mathrm{H} \ldots \pi$ hydrogen bonding and $\pi-\pi$ interactions.

Molecular pairs of the compound I extracted from crystal structure along with their respective interaction energies are shown in figure 3 . The maximum stabilization to the crystal structure comes from $\pi-\pi$ interaction between anthracene ring systems. The stabilization energy of this pair is -11.06 kcal $\mathrm{mol}^{-1}$ obtained using PIXEL with major contribution from dispersion component. The next most stabilized pair (Motif 2) shows the presence of bifurcated acceptor atom $\mathrm{O} 1$ with $\mathrm{H} 5$ and $\mathrm{H} 7$ having interaction energy of $-10.47 \mathrm{kcal} \mathrm{mol}^{-1}$. The next most stabilized pair (Motif 3) involves $\mathrm{C} 12 \ldots \mathrm{Cl} 1$ and $\mathrm{C} 13$...Cl1 interactions. Along with these interactions it also involves in molecular stacking (C-C stacking) and hence results in a total interaction energy of $-8.19 \mathrm{kcal} \mathrm{mol}^{-1}$. The next molecular pair (Motif 4) shows the presence of $\mathrm{C}-\mathrm{H}$. . .C interaction involving $\mathrm{H} 20$ interacting with $\mathrm{C} 1$ and bifurcated donor atom $\mathrm{C} 21$ interacting with $\mathrm{C} 6$ and $\mathrm{C} 7$, generating dimers with stabilization energy of $-6.14 \mathrm{kcal} \mathrm{mol}^{-1}$. The maximum stabilization to the next molecular pair (Motif 5) comes from $\mathrm{C}-\mathrm{H}$. . . $\pi$ intermolecular interactions involving $\mathrm{H} 19$ with $\mathrm{C} 4$ and $\mathrm{C} 5$ of $\mathrm{Cg} 1$ [where $\mathrm{Cg} 1$ is the centroid of benzene ring $(\mathrm{C} 1-\mathrm{C} 6)]$ and $\mathrm{H} 15$ interacting with $\mathrm{Cg} 4$ [where $\mathrm{Cg} 4$ is the centroid of benzene ring $(\mathrm{C} 18-\mathrm{C} 23)]$. The stabilization energy of this pair is $-4.54 \mathrm{kcal} \mathrm{mol}^{-1}$ obtained using PIXEL. Molecular pair 6 shows the presence of $\mathrm{C}-\mathrm{H}$. . .C (involving $\mathrm{H} 12$ with $\mathrm{C} 2$ ) and $\mathrm{C}-\mathrm{H}$...Cl interaction (involving $\mathrm{H} 8$ with $\mathrm{Cl1}$ ), resulting in a stabilization energy of $-3.51 \mathrm{kcal} \mathrm{mol}^{-1}$. Another molecular pair (Motif 7) shows the presence of bifurcated acceptor atom $\mathrm{Cl} 1$ interacting with $\mathrm{H} 13$ and $\mathrm{H} 14$ having interaction energy of $-3.08 \mathrm{kcal} \mathrm{mol}^{-1}$ with major contribution from dispersion component. The next most stabilized molecular pair (Motif 8) again involves in $\mathrm{C}-\mathrm{H}$...Cl hydrogen bonding involving $\mathrm{H} 2$ interacting with $\mathrm{Cl} 1$ with an interaction energy of $-2.58 \mathrm{kcal} \mathrm{mol}^{-1}$ and the stabilization mainly comes from dispersion component, providing additional stabilization to the crystal packing. The combined nature of all these interactions is mainly dispersive in nature.

The molecular structure of II is shown in figure 4. In title compound II, $\mathrm{C}_{23} \mathrm{H}_{15} \mathrm{~N}_{1} \mathrm{O}_{3}$, the prop-2-en-1-one unit is 

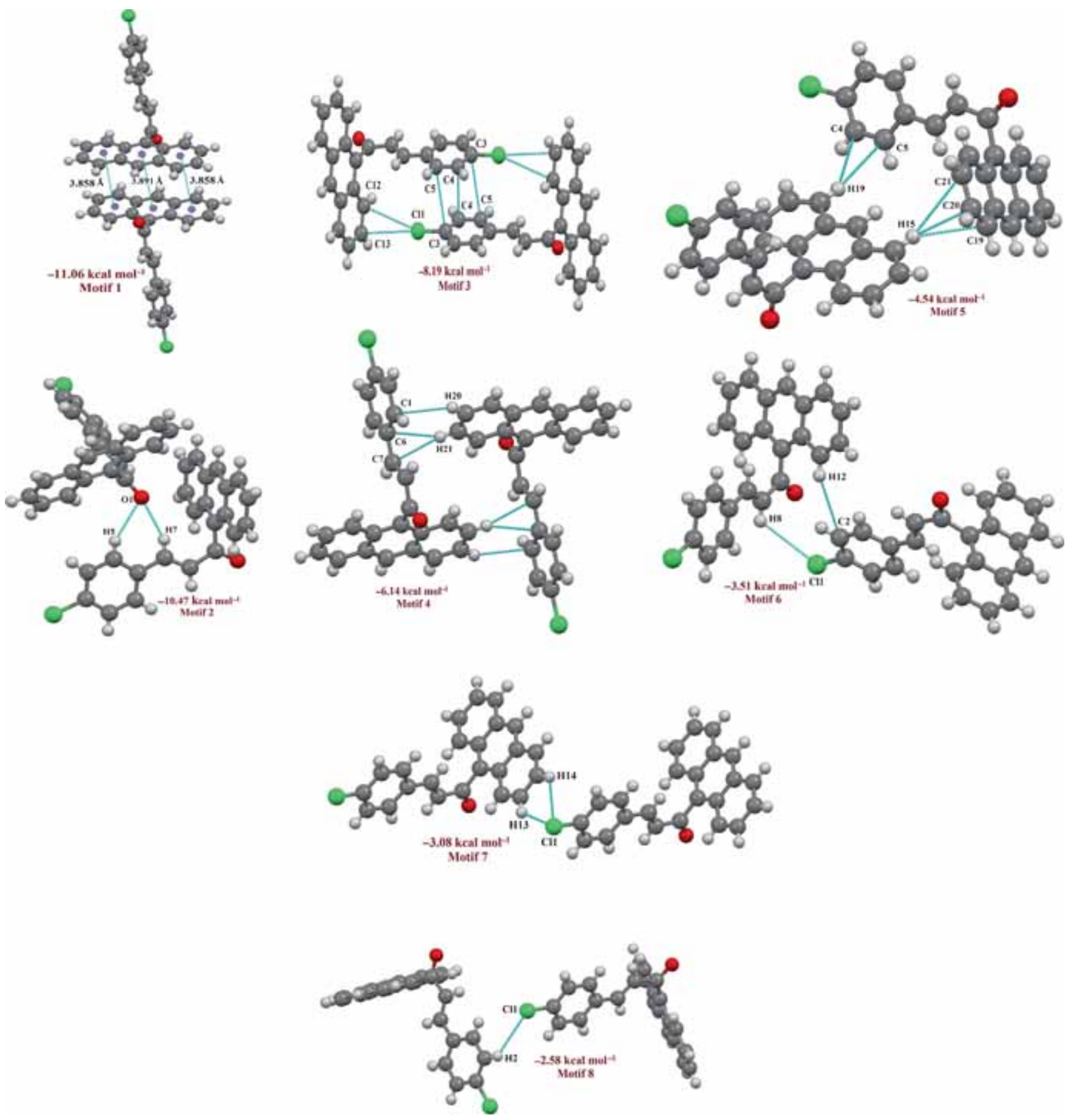

Figure 3. Molecular pairs (1-8) with their interaction energies for compound $\mathbf{I}$.

also planar and it makes dihedral angles of $7.30(23)^{\circ}$ and $86.96(17)^{\circ}$, respectively, with the 4-nitrophenyl ring and the anthracene ring system. In this compound the anthracene ring system is planar and the molecule is twisted as indicated by the interplanar angle between the 4-nitrorophenyl ring and the anthracene ring system, which is $88.87(6)^{\circ}$. The pro2-en-1-one unit (C7-C9/O1) is planar as evidenced by the torsion angle $\mathrm{O} 1-\mathrm{C} 9-\mathrm{C} 8-\mathrm{C} 7$ of $177.9(2)^{\circ}$. The O-N-O angle in the $\mathrm{NO}_{2}$ group is significantly greater than $120^{\circ}$ as a result of the lone pair of electrons on each of the $\mathrm{O}$ atoms; this effect is predicted by the valence-shell electronpair repulsion theory $[29,30]$. The length of the double bond $\mathrm{C} 9=\mathrm{O} 1$ is confirmed by the respective distance of $1.223(2) \AA$. Molecule II adopts a trans-(-)gauche-trans (tgt) conformation [torsion angles $\left({ }^{\circ}\right)$ : $\mathrm{C} 6-\mathrm{C} 7-\mathrm{C} 8-\mathrm{C} 9,-178.7(2)$; C7-C8-C9-C10, -2.6(4); C7-C8-C9-O1, 177.9(2)]. Three 


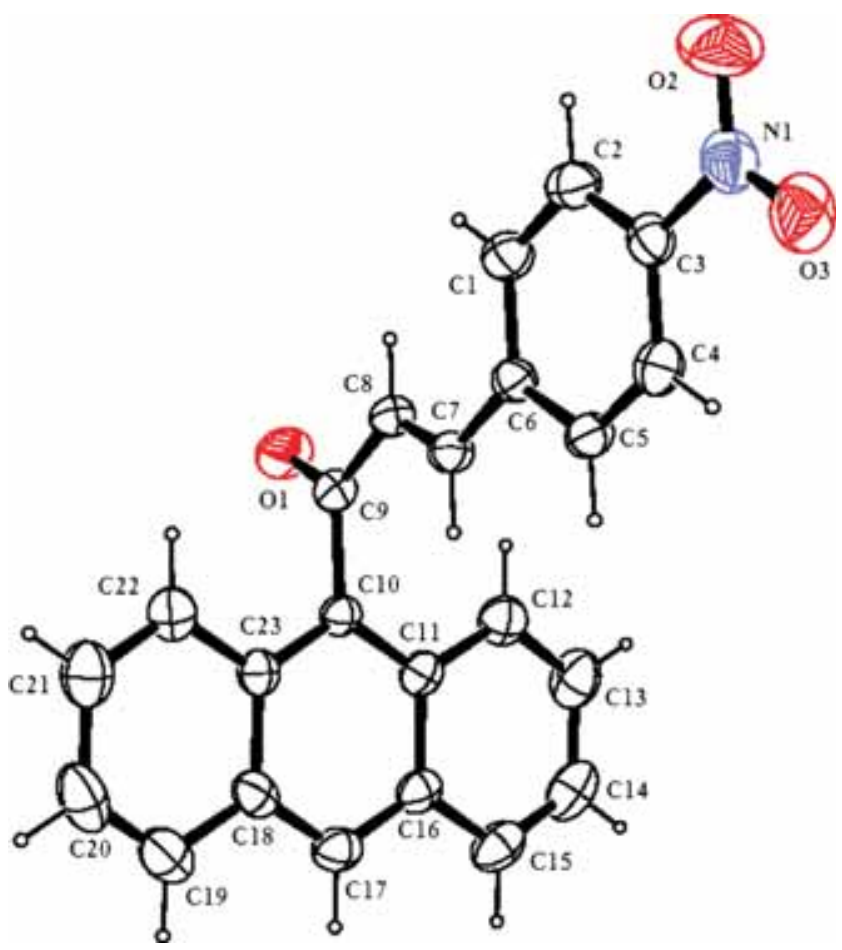

Figure 4. Molecular structure of II, showing the atomic labelling scheme. Displacement ellipsoids are drawn at $30 \%$ probability level.

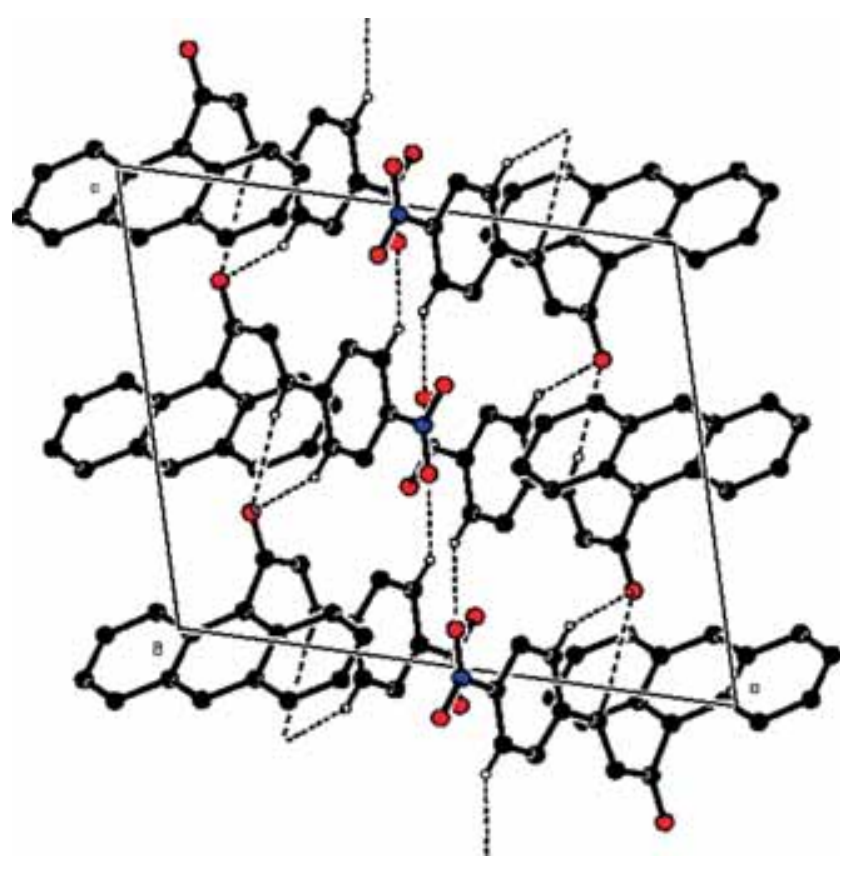

Figure 5. Crystal packing of compound II, viewed along the $a$ axis, showing hydrogen bonding (dashed lines).

$\mathrm{C}-\mathrm{H} \cdots \mathrm{O}$ inter molecular hydrogen bond interactions are observed. These intermolecular interactions are responsible for maintaining the crystal packing. The crystal structure is further stabilized by $\mathrm{C}-\mathrm{H} \ldots \pi$ and $\pi \ldots \pi$ interactions shown in figure 5 .

Molecular pairs of compound II extracted from its crystal structure along with their respective interaction energies are shown in figure 6 . The maximum stabilization to the crystal structure comes from $\mathrm{C}-\mathrm{H}$. .. O interaction involving bifurcated acceptor atom $\mathrm{O} 1$ with $\mathrm{H} 5$ and $\mathrm{H} 7$ having interaction energy of $-12.14 \mathrm{kcal} \mathrm{mol}^{-1}$. The molecular pair (Motif 1) in this compound II is similar to the most stabilized motif (Motif 2) in compound I. The next most stabilized pair (Motif 2) in this compound $\mathbf{~ I I}$ is also similar to the most stabilized Motif 1 in compound $\mathbf{I}$, resulting in a stabilization energy of $-11.54 \mathrm{kcal} \mathrm{mol}^{-1}$. The third most stabilized interacting motif (Motif 3) shows the presence of C6. . .O3 and C7 . .O3 interactions. Along with these interactions it also involves in $\pi-\pi$ interactions, resulting in a total interaction energy of $-7.24 \mathrm{kcal} \mathrm{mol}^{-1}$. The next molecular pair (Motif 4) shows the presence of $\mathrm{C}-\mathrm{H} . \ldots \pi$ and $\mathrm{C}-\mathrm{H}$. . .C interaction involving $\mathrm{H} 13$ interacting with $\mathrm{Cg} 1$ [where $\mathrm{Cg} 1$ is the centroid of benzene ring $(\mathrm{C} 1-\mathrm{C} 6)]$ and $\mathrm{H} 14$ interacting with $\mathrm{C} 2$, generating dimers and resulting in a stabilization energy of -5.18 $\mathrm{kcal} \mathrm{mol}^{-1}$. The maximum stabilization to the next molecular pair (Motif 5) comes from $\mathrm{C}-\mathrm{H} . . . \pi$ intermolecular interactions involving $\mathrm{H} 19$ with $\mathrm{C} 13$ and $\mathrm{C} 14$ of $\mathrm{Cg} 3$ [where $\mathrm{Cg} 3$ is the centroid of benzene ring $(\mathrm{C} 11-\mathrm{C} 16)]$ and $\mathrm{H} 15$ interacting with $\mathrm{Cg} 1$ [where $\mathrm{Cg} 1$ is the centroid of benzene ring $(\mathrm{C} 1-$ C6)]. The stabilization energy of this pair is $-4.37 \mathrm{kcal} \mathrm{mol}^{-1}$ obtained using PIXEL. Molecular pair 6 shows the presence of $\mathrm{C}-\mathrm{H}$... O (involving $\mathrm{H} 8$ with $\mathrm{O} 2$ ) interaction resulting in a stabilization energy of $-3.94 \mathrm{kcal} \mathrm{mol}^{-1}$. The combined nature of all these interactions in compound II is mainly dispersive in nature again.

\section{Conclusions}

The molecular and crystal structure of chalcone derivatives has been elucidated by X-ray diffraction methods and the results show the presence of different key structural motifs, which aid stabilization of crystal packing in the unit cell. The total interaction energy (lattice energy) appears to be the same for both the compounds $\left[-39.08 \mathrm{kcal} \mathrm{mol}^{-1}\right.$ for compound $\mathbf{I}$ and $-38.12 \mathrm{kcal} \mathrm{mol}^{-1}$ for compound $\left.\mathbf{I I}\right]$. The present study can help us in designing different biologically active derivatives of chalcone by changing the strength of donor and/or acceptor atom, which can give rise to interactions of different strength and nature, which in turn can help in identifying binding capabilities of such molecules with enzymes. In summary, the results demonstrated that the calculation of lattice energies is a useful approach to assess the stability of molecular crystals in which dispersion-type interactions make up an essential part of the intermolecular interactions. 

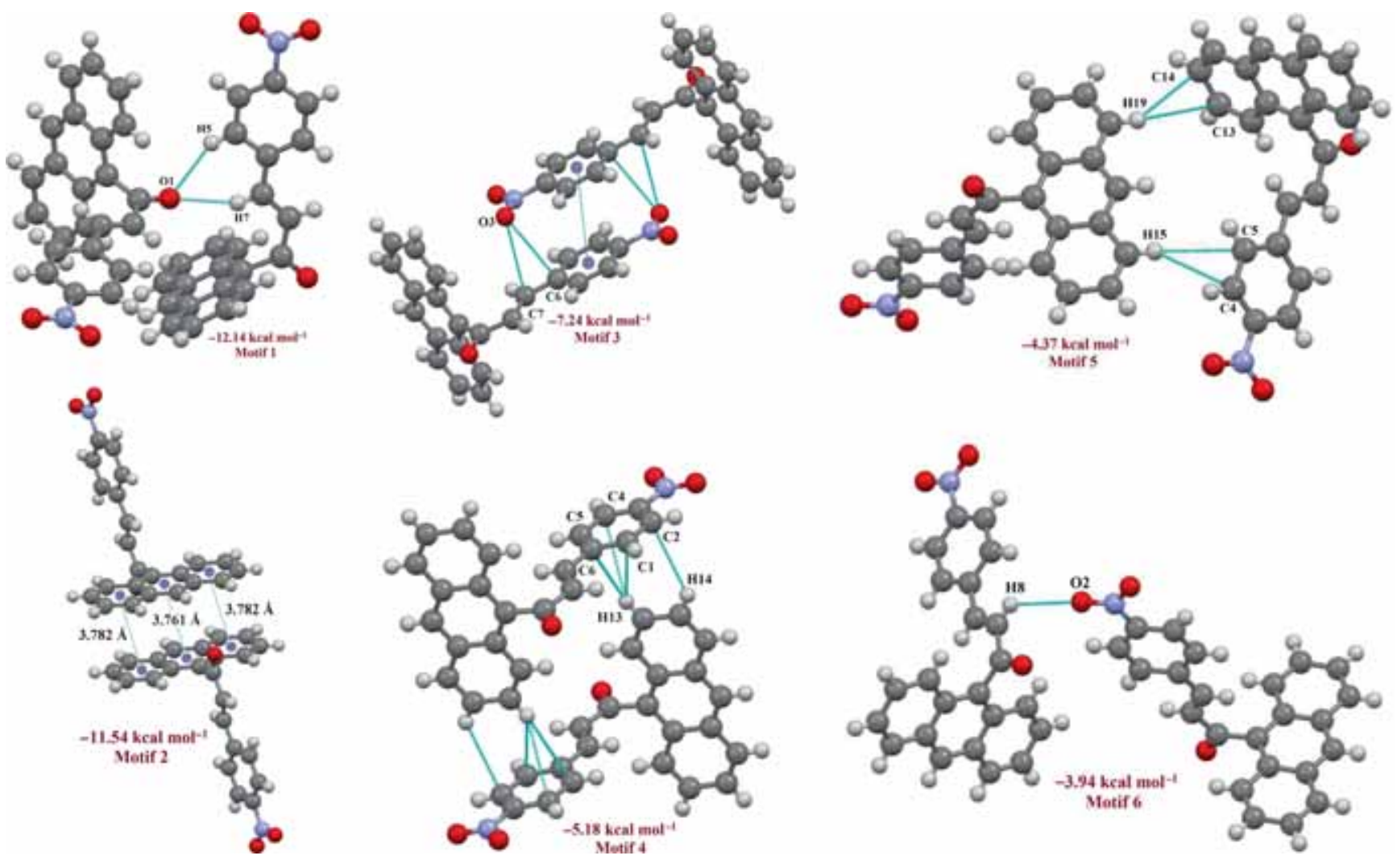

Figure 6. Molecular pairs (1-6) with their interaction energies for compound II.

\section{Acknowledgements}

RK acknowledges the Department of Science and Technology for the Single-Crystal X-ray Diffractometer sanctioned as a National Facility under Project No. SR/S2/CMP-47/2003. BN thanks UGC for financial assistance through BSR onetime grant for the purchase of chemicals. VVS thanks Mangalore University for research facilities.

\section{References}

[1] Wong E 1968 Phytochemistry 71751

[2] Belofsky G, Percivill D, Lewis K, Tegos G P and Ekart J 2004 J. Nat. Prod. 67481

[3] Nielsen S F, Christensen S B, Cruciani G, Kharazmi A and Liljefors T 1998 J. Med. Chem. 414819

[4] Wang L, Chen G, Lu X, Wang S, Han S, Li Y, Ping G, Jiang X, Li H, Yang J and Wu C 2015 Eur. J. Med. Chem. 8988

[5] Dimmock J R, Elias D W, Beazely M A and Kandepu N M 1999 Curr. Med. Chem. 61125

[6] Lopez S N, Castelli M V, Zacchino S A, Dominguez J N, Lobo G, Jaime C C, Cortes J C G, Ribas J C, Devia C, Ana M R and Ricardo D E 2001 Bioorg. Med. Chem. 9 1999

[7] Agarwal A, Srivastava K, Puri S K and Chauhan P M S 2005 Bioorg. Med. Chem. 134645
[8] Kumar D, Kuma N M, Tantak M P, Ogura M, Kusaka E and Ito T 2014 Bioorg. Med. Chem. 245170

[9] Fang Q, Zhao L, Wang Y, Zhang Y, Li Z, Pan Y, Kanchana K, Wang J, Tong C, Li D and Liang G 2015 Toxicol. Appl. Pharm. 282129

[10] Samshuddin S, Narayana B, Shetty D N and Raghavendra R 2011 Der. Pharma. Chem. 3232

[11] Baktir Z, Akkrut M, Samshuddin S, Narayana B and Yathirajan H S 2011 Acta Crystallogr. E 67 o1292

[12] Sapnakumari M, Narayana B, Sarojini B K and Madhu L N 2014 Med. Chem. Res. 232368

[13] Poornesh P, Shettigar S, Umesh G, Manjunatha K B, Kamath K P, Sarojini B K and Narayana B 2009 Opt. Mater. 31 854

[14] Jasinski J P, Guild C J, Samshuddin S, Narayana B and Yathirajan H S 2010 Acta Crystallogr. E 66 o2018

[15] Butcher R J, Yathirajan H S, Anilkumar H G, Sarojini B K and Narayana B 2006 Acta Crystallogr. E 62 o1633

[16] Narayana B, Salian V V, Sarojini B K and Jasinski J P 2014 Acta Crystallogr. E $\mathbf{7 0}$ o855

[17] Harrison W T A, Yathirajan H S, Sarojini B K, Narayana B and Vijay Raj K K 2006 Acta Crystallogr. E 6201578

[18] Oxford Diffraction 2010 CrysAlis PRO (Yarnton, England: Oxford Diffraction Ltd)

[19] Sheldrick G M 2008 Acta Crystallogr. A 64112

[20] Farrugia L J 1999 J. Appl. Crystallogr. 32837

[21] Spek A L 2009 Acta Crystallogr. D 65148 
[22] Nardelli M 1995 J. Appl. Crystallogr. 28659

[23] Gavezzotti A 2011 New J. Chem. 351360

[24] Dunitz J D and Gavezzotti A 2012 Cryst. Growth Des. 12 5873

[25] Maschio L, Civalleri B, Ugliengo P and Gavezzotti A $2011 \mathrm{~J}$. Phys. Chem. A 11511179
[26] Dunitz J D and Gavezzotti A 2005 Chem. Soc. Rev. 382622

[27] Farrugia L J 2012 J. Appl. Crystallogr. 45849

[28] Allen F H, Kennard O, Watson D G, Brammer L, Prpen A G and Taylor R 1987 J. Chem. Soc. Perkin Trans. 2 S1

[29] Gillespie R J 1963 J. Chem. Educ. 40295

[30] Gillespie R J 1992 Chem. Soc. Rev. 2159 